\title{
Modeling and Dynamic Characteristic Analysis of a Ball Screw Feed Drive System Based on Receptance Coupling
}

\author{
Fengqing TIAN, Jianmin ZHU*, Xiaoru LI, Zhiwen HUANG
}

\begin{abstract}
Modeling and modal analysis method based on receptance coupling are proposed for a vibration mode of a ball screw feed drive system, which cannot be determined by axial and torsional modal shape curves through a traditional method. In this study, the mathematical model for ball screw feed drive system is obtained by improved receptance coupling. The natural frequencies of different assembly states are calculated in the modeling process. The vibration modes of the feed drive system are determined by comparing the natural frequency distributions of different assembly states for a detailed analysis of the dynamic characteristics of the feed drive system. In the proposed method, a self-developed ball screw feed drive system is selected to study the influence of worktable position, worktable mass, and screw lead on the dynamic characteristics of the ball screw feed drive system. A change in the worktable position mainly affects the vibration of the ball screw itself. A change in the worktable mass mainly affects the coupling vibration between the ball screw and the rotor or bearing. The screw lead has an opposite influence on axial and torsional vibrations of the feed drive system, and the stability of the feed drive system improves with the screw lead. The validity of the proposed method is verified by the case study.
\end{abstract}

Keywords: ball screw feed drive system; dynamic characteristic analysis; receptance coupling

\section{INTRODUCTION}

A ball screw feed drive system is extensively used in machine tools. Reliable theoretical modeling and dynamic characteristic analysis of such a system are vital for the performance research and subsequent design of machine tools $[1,2]$. The precise modeling and dynamic analysis of feed drive systems are becoming increasingly important with the development of feed drive systems to high speed and precision. The traditional dynamic characteristic analysis of ball screw feed drive systems adopts lumped parameter model $[3,4]$ and finite element model $[5,6]$. However, neither model can simulate ball screw system well.

A rigid-flexible coupling model has been frequently used in recent research. This kind of model combines the advantages of the finite element and lumped parameter models. Zhang et al. [7] established a rigid-flexible model of the feed drive system and analyzed the change rule of a natural frequency with the change in feed speed. Zhou et al. [8] verified the influence of the gravity center of the worktable on the dynamic characteristics of the feed drive system through simulation and experiment. Frey et al. [9] focused on analyzing the axial characteristics of the feed drive system under various working and coupling conditions. The influence of the factors on the dynamic characteristics of the feed drive system is analyzed in the abovementioned literature. However, we not only concentrate on these influences but also aim to determine the reasons for the existence of these influences to guide our design.

A traditional method for solving the abovementioned problem is modal shape analysis, and research on modal shape analysis of a feed drive system is limited. In Varanasi et al. [10] according to the analysis of the modal shape, the axial and torsional vibrations of a system are coupled. Dong et al. [11] through the modal shape analysis determined that the vibration of each mode is axial, torsional, or transverse. Vicente et al. [12] studied the coupling degree between axial and torsional vibrations. Through the modal shape analysis, Vicente et al. determined that the second and fourth modes are axial and torsional vibrations, respectively. However, determining the third mode is difficult. To solve this problem, they determined that the third mode is a torsional vibration through the natural frequency distribution of three assembly states.

In the modal shape analysis of the abovementioned research, the modal shape of the feed drive system is reflected as the modal shape of the axial and torsional vibrations of the ball screw. However, the ball screw is a slender shaft, and the modal shape curve of its axial and torsional vibrations is not equally intuitive as the transverse modal shape curve. The vibration mode of the ball screw through the modal shape curve of axial or torsional vibration is difficult to determine. Therefore, typical problems in the traditional modal shape research arise: the kind of axial or torsional vibration is difficult to identify. To solve the abovementioned problem, the feed drive system is divided into more assembly states in this study than in Literature 12. However, the modeling method in Literature 12 cannot divide the feed drive system into more assembly states.

In this study, receptance coupling method was used for modeling. The modeling process of receptance coupling is similar to assembly process of equipment. Therefore, the mathematical model of each assembly state can be obtained during the modeling process. In the current study, the receptance coupling has been mainly used for the modeling and dynamic characteristic analysis of a spindle system in a milling machine [13-15]. Research on the modeling and dynamic characteristic analysis of ball screw feed drive systems by receptance coupling is scarce. Liu et al. [16] established the mathematical model of a two-axis feed drive system by receptance coupling. Due to the worktable as a rigid body in the modeling, the rigid body itself has no FRF. Liu regarded worktable, carriage and the joint between them as a substructure, and the feed drive system modeling was obtained through coupling the FRF of this substructure. However, there is only one worktable in the single-axis feed drive system, and cannot obtain the FRF. Therefore, the Liu's method is inapplicable to a single-axis feed drive system. However, the dynamic analysis of single-axis feed drive system is also important for the study of the dynamic characteristics of machine tools [17]. Therefore, a new substructure division method is proposed 
in accordance with the structural characteristics of the ball screw feed drive system. The ball screw is divided into several segments, and the segment that is connected to the worktable is simulated by lumped parameters. The segment and worktable are considered as one substructure to solve the modeling problem of the single-axis feed drive system.

In summary, a modeling method based on a new substructure division method is proposed for the problem that the single-axis feed drive system cannot be modeled by the existing receptance coupling. Given that the vibration modes cannot be determined using the modal shape curve of ball screw feed drive systems, the modal analysis method based on the assembly state is proposed. Finally, this study uses a test bench for a ball screw feed drive system as an example to study and analyze the first four vibration modes of the feed drive system through the proposed method.

\section{MODELING OF THE BALL SCREW FEED DRIVE SYSTEM}

The structure of the high-speed and high-precision ball screw feed drive system is illustrated in Fig. 1. The axial feed precision of the worktable is the key point of the ball screw feed drive system research, and the axial vibration and torsional vibration of the ball screw have great influence on the axial vibration of the worktable.

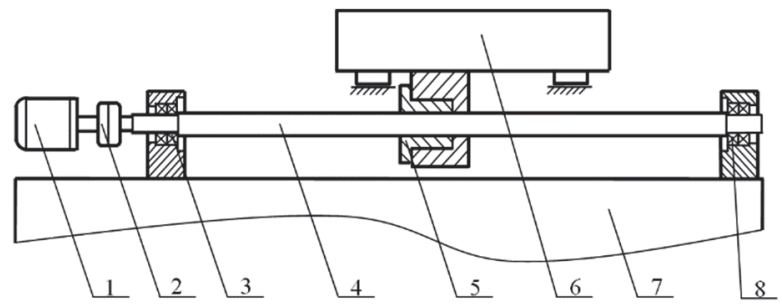

Figure 1 Ball screw feed drive system:

1) Servo motor, 2) Coupling, 3) Left bearing group, 4) Ball screw, 5) Screw nut, 6) Worktable, 7) Bed, 8) Right bearing group

Therefore, the simplified model of the feed drive system mainly considers the axial and torsional vibration of ball screw and axial vibration of the worktable, as depicted in Fig. 2.

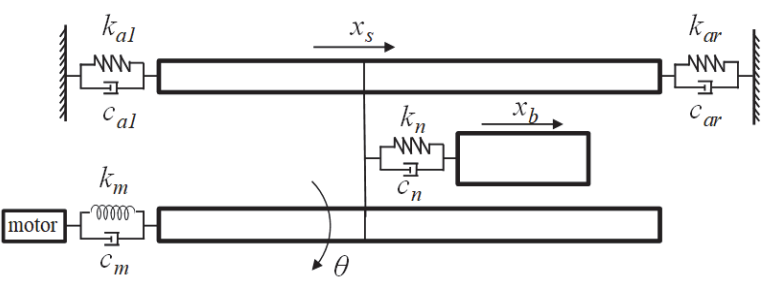

Figure 2 Simplified model of the ball screw feed drive system

In Fig. 2, $x_{s}$ represents axial vibration of the ball screw, $x_{b}$ represents axial vibration of the worktable, $\theta$ represents torsional vibration of the ball screw. $k_{a l}$ and $c_{a l}$ are the axial stiffness and damping provided by the left-bearing group, respectively. $k_{a r}$ and $c_{a r}$ are the axial stiffness and damping provided by the right-bearing group, correspondingly. Moreover, $k_{m}$ and $c_{m}$ are the torsional stiffness and damping of coupling, respectively. $k_{n}$ and $c_{n}$ correspond to the axial stiffness and damping of ball screw pairs.

\subsection{Assembly State Division of the Ball Screw Feed Drive System}

In order to solve the problem that the existing receptance coupling method cannot model the worktable of single-axis feed drive system, we proposed a new substructure division method according to the application of lumped parameter model in the ball screw feed system. The FRF of the worktable is represented by the FRF of the substructure composed with a part of the ball screw and the worktable. The method can be used not only for the modeling of single-axis but also for the multi-axis feed drive system.

The ball screw is divided into four segments, namely, A, B, F, and H, as exhibited in Fig. 3. Segments F and $\mathrm{H}$ are the parts that are in contact with the screw nut and coupling, respectively. The segment of the ball screw between Segments F and $\mathrm{H}$ is Segment A, while the rest comprises Segment B. All four segments are rigidly connected. Segments A and B of the ball screw are simulated as elastic shafts with free ends. Segments F and $\mathrm{H}$ are simulated by the lumped parameter model. Fig. 3 displays the substructures of the ball screw feed drive system. The axial substructure contains the axial models of $\mathrm{A}, \mathrm{B}$, and the bearing. The torsional substructure contains the torsional models of $\mathrm{A}, \mathrm{B}, \mathrm{H}$, and the rotor. The worktable substructure contains the worktable and the axial and torsional models of F. The FRFs of this substructure can be obtained through the finite element method. During the modeling of the feed drive system, the FRFs of the axial and torsional substructures are coupled separately to Segment $F$ with the same degree of freedom.

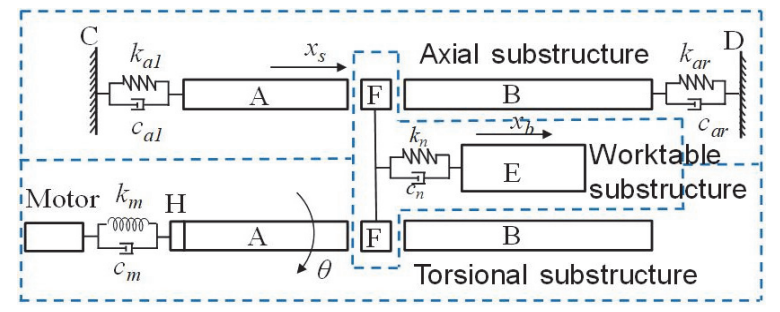

Figure 3 Substructures of the ball screw feed drive system

This study must investigate the natural frequency distribution of the simplified model under different assembly states. Thus, the ball screw feed drive system is divided into seven assembly states.

\subsection{Assembly of the Axial Substructure}

The axial substructure model of the feed drive system is illustrated in Fig. 4.

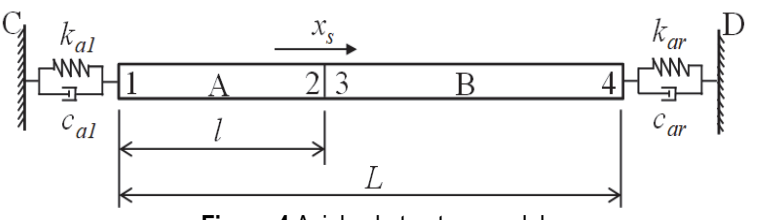

Figure 4 Axial substructure model

For expressing the FRF of the substructure, 1 to 4 are regarded as the excitation and response points. In addition, $l$ is the length of $\mathrm{A}$, and $L$ is the total length of the ball screw. 


\subsubsection{Unassembled State of the Ball Screw Axial Vibration}

$A$ and $B$ are circular shafts with free ends, and the axial FRF matrix is directly calculated using Eqs. (1) and (2) [18].

$$
\begin{aligned}
& \boldsymbol{H}_{\mathrm{A}-a}(l)=\left[\begin{array}{ll}
h_{\mathrm{A}-a 11}(l) & h_{\mathrm{A}-a 12}(l) \\
h_{\mathrm{A}-a 21}(l) & h_{\mathrm{A}-a 22}(l)
\end{array}\right]= \\
& =(E S \lambda)^{-1}\left[\begin{array}{ll}
-\cos (\lambda l) & -\csc (\lambda l) \\
-\csc (\lambda l) & -\cos (\lambda l)
\end{array}\right] \\
& \boldsymbol{H}_{\mathrm{B}-a}(l)=\left[\begin{array}{ll}
h_{\mathrm{B}-a 33}(l) & h_{\mathrm{B}-a 34}(l) \\
h_{\mathrm{B}-a 43}(l) & h_{\mathrm{B}-a 44}(l)
\end{array}\right]= \\
& =(E S \lambda)^{-1}\left[\begin{array}{ll}
-\cos [\lambda(L-l)] & -\csc [\lambda(L-l)] \\
-\csc [\lambda(L-l)] & -\cos [\lambda(L-l)]
\end{array}\right]
\end{aligned}
$$

where $\mathrm{A}$ and $\mathrm{B}$ indicate the substructures, and $a$ denotes the axial FRF. $\boldsymbol{H}_{\mathrm{A}-a}$ is the axial FRF matrix of Segment A, $h_{\mathrm{A}-}$ $a 12$ is the axial FRF with response at Point 1 and excitation at Point 2, $E$ is the elasticity modulus of the ball screw, $S$ is the cross-sectional area of the ball screw, $\omega$ is the angular frequency, and $\rho$ is the density of the ball screw. $\lambda$ is expressed in Eq. (3).

$$
\lambda=\omega \sqrt{\rho / E}
$$

The connection between $\mathrm{A}$ and $\mathrm{B}$ depicts a rigid coupling. The FRF matrix of the ball screw in the unassembled state can be obtained by coupling A and B in accordance with the receptance coupling method; this coupling is expressed as $\boldsymbol{H}_{\mathrm{AB}-a}$.

$$
\begin{aligned}
& \boldsymbol{H}_{\mathrm{AB}-a}(l)=\left[\begin{array}{lll}
h_{\mathrm{AB}-a 11}(l) & h_{\mathrm{AB}-a 12}(l) & h_{\mathrm{AB}-a 14}(l) \\
h_{\mathrm{AB}-a 21}(l) & h_{\mathrm{AB}-a 22}(l) & h_{\mathrm{AB}-a 24}(l) \\
h_{\mathrm{AB}-a 41}(l) & h_{\mathrm{AB}-a 42}(l) & h_{\mathrm{AB}-a 44}(l)
\end{array}\right]= \\
& =\left[\begin{array}{ccc}
h_{\mathrm{A}-a 11}(l) & h_{\mathrm{A}-a 12}(l) & 0 \\
h_{\mathrm{A}-a 21}(l) & h_{\mathrm{A}-a 22}(l) & 0 \\
0 & 0 & h_{\mathrm{B}-a 44}(l)
\end{array}\right]+\left[\begin{array}{c}
-h_{\mathrm{A}-a 12}(l) \\
-h_{\mathrm{A}-a 22}(l) \\
h_{\mathrm{B}-a 43}(l)
\end{array}\right] \\
& {\left[h_{\mathrm{A}-a 22}(l)+h_{\mathrm{B}-a 33}(l)\right]^{-1}\left[\begin{array}{c}
h_{\mathrm{A}-a 21}(l) \\
h_{\mathrm{A}-a 22}(l) \\
-h_{\mathrm{B}-a 34}(l)
\end{array}\right]^{\mathrm{T}}}
\end{aligned}
$$

\subsubsection{Assembly State of the Ball Screw and Bearing}

Bed $\mathrm{C}$ is regarded as the rigid body and is fixed to the ground. Thus, the axial FRF of $\mathrm{C}$ is expressed as follows:

$h_{\mathrm{C}-a}=0$

The joint between the ball screw and $\mathrm{C}$ is simulated by a spring damper. Thus, the axial FRF of the joint is expressed as follows:

$h_{\mathrm{J}-a l}=\left[\frac{1}{k_{a l}+i \omega c_{a l}}\right]^{-1}$

$\boldsymbol{H}_{\mathrm{AC}-\mathrm{a}}$ is obtained by coupling the FRFs of the ball screw and $\mathrm{C}$.

$$
\boldsymbol{H}_{\mathrm{AC}-a}(l)=\left[\begin{array}{lll}
h_{\mathrm{AC}-a 11}(l) & h_{\mathrm{AC}-a 12}(l) & h_{\mathrm{AC}-a 14}(l) \\
h_{\mathrm{AC}-a 21}(l) & h_{\mathrm{AC}-a 22}(l) & h_{\mathrm{AC}-a 24}(l) \\
h_{\mathrm{AC}-a 41}(l) & h_{\mathrm{AC}-a 42}(l) & h_{\mathrm{AC}-a 44}(l)
\end{array}\right]=\boldsymbol{H}_{\mathrm{AB}-a}(l)+\left[\begin{array}{c}
-h_{\mathrm{AB}-a 11}(l) \\
-h_{\mathrm{AB}-a 21}(l) \\
-h_{\mathrm{AB}-a 41}(l)
\end{array}\right]\left[h_{\mathrm{AB}-a 11}(l)+h_{\mathrm{J}-a l}+h_{\mathrm{C}-a}\right]^{-1}\left[\begin{array}{c}
h_{\mathrm{AB}-a 11}(l) \\
h_{\mathrm{AB}-a 12}(l) \\
h_{\mathrm{AB}-a 14}(l)
\end{array}\right]^{\mathrm{T}}
$$

$\mathrm{D}$ also represents the bed. Two letters represent the bed because two joints exist between the bed and the ball screw. The coupling method in this subsection is similar to the previous method and is no longer elaborated. The FRF matrix of the obtained axial substructure is expressed as $\boldsymbol{H}_{\mathrm{AD}-a}$.

$$
\boldsymbol{H}_{\mathrm{AD}-a}(l)=\left[\begin{array}{lll}
h_{\mathrm{AD}-a 11}(l) & h_{\mathrm{AD}-a 12}(l) & h_{\mathrm{AD}-a 14}(l) \\
h_{\mathrm{AD}-a 21}(l) & h_{\mathrm{AD}-a 22}(l) & h_{\mathrm{AD}-a 24}(l) \\
h_{\mathrm{AD}-a 41}(l) & h_{\mathrm{AD}-a 42}(l) & h_{\mathrm{AD}-a 44}(l)
\end{array}\right]=\boldsymbol{H}_{\mathrm{AC}-a}(l)+\left[\begin{array}{c}
-h_{\mathrm{AC}-a 14}(l) \\
-h_{\mathrm{AC}-a 24}(l) \\
-h_{\mathrm{AC}-a 44}(l)
\end{array}\right]\left[h_{\mathrm{AC}-a 44}(l)+h_{\mathrm{J}-a r}\right]^{-1}\left[\begin{array}{l}
h_{\mathrm{AC}-a 41}(l) \\
h_{\mathrm{AC}-a 42}(l) \\
h_{\mathrm{AC}-a 44}(l)
\end{array}\right]^{\mathrm{T}}
$$

\subsection{Assembly of the Torsional Substructure}

The torsional substructure model of the feed drive system is illustrated in Fig. 5.

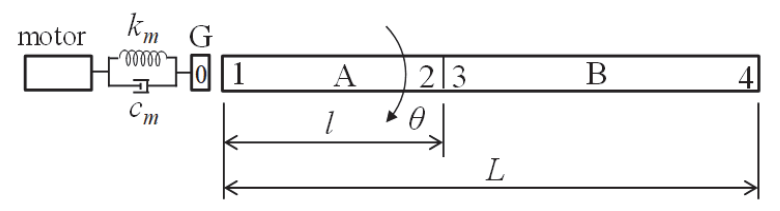

Figure 5 Torsional substructure model

\subsubsection{Unassembled State of the Ball Screw Torsional Vibration}

A and B of the ball screw are circular shafts with free ends. The torsion FRF matrix is calculated using Eqs. (9) and (10) [18].

$$
\begin{aligned}
& \boldsymbol{H}_{\mathrm{A}-t}(l)=\left[\begin{array}{ll}
h_{\mathrm{A}-t 11}(l) & h_{\mathrm{A}-t 12}(l) \\
h_{\mathrm{A}-t 21}(l) & h_{\mathrm{A}-t 22}(l)
\end{array}\right]= \\
& =(G J \lambda)^{-1}\left[\begin{array}{ll}
-\cot (\lambda l) & -\csc (\lambda l) \\
-\csc (\lambda l) & -\cot (\lambda l)
\end{array}\right]
\end{aligned}
$$




$$
\begin{aligned}
& \boldsymbol{H}_{\mathrm{B}-t}(l)=\left[\begin{array}{ll}
h_{\mathrm{B}-t 33}(l) & h_{\mathrm{B}-t 34}(l) \\
h_{\mathrm{B}-t 43}(l) & h_{\mathrm{B}-t 44}(l)
\end{array}\right]= \\
& =(G J \lambda)^{-1}\left[\begin{array}{ll}
-\cot [\lambda(L-l)] & -\csc [\lambda(L-l)] \\
-\csc [\lambda(L-l)] & -\cot [\lambda(L-l)]
\end{array}\right]
\end{aligned}
$$

where $\boldsymbol{H}_{\mathrm{A}-t}$ and $\boldsymbol{H}_{\mathrm{B}-t}$ are the torsion FRF matrices of A and $\mathrm{B}$, correspondingly, $t$ indicates the torsion FRF, $G$ is the shear elasticity of the ball screw, and $\mathrm{d}$ is the diameter of the ball screw. Moreover, $J$ is defined as follows:

$J=\pi \mathrm{d}^{4} / 32$

The connection between $\mathrm{A}$ and $\mathrm{B}$ is rigid coupling. The FRF matrix of the ball screw in the unassembled state can be obtained by coupling $\mathrm{A}$ and $\mathrm{B}$; this coupling is expressed as $\mathrm{H}_{\mathrm{AB}-t}$.

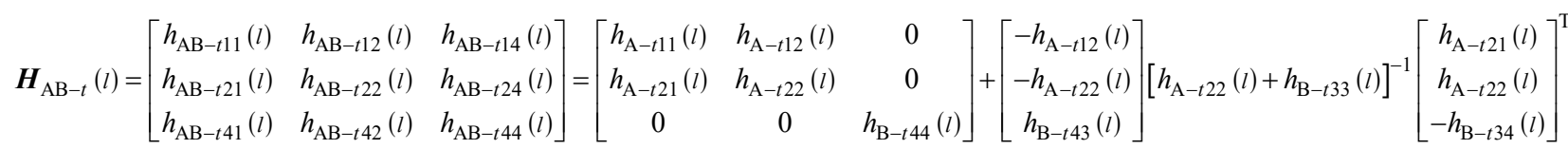

$\boldsymbol{C}_{\mathrm{H}}=\left[\begin{array}{cc}c_{\mathrm{m}} & -c_{\mathrm{m}} \\ -c_{\mathrm{m}} & c_{\mathrm{m}}\end{array}\right]$

The rotor of the motor and $\mathrm{H}$ of the ball screw are connected by coupling, as displayed in Fig. 5. According to finite element theory, mass matrix $\boldsymbol{M}_{\mathrm{H}}$, stiffness matrix $\boldsymbol{K}_{\mathrm{H}}$, and damping matrix $\boldsymbol{C}_{\mathrm{H}}$ are obtained as follows:

$$
\begin{aligned}
& \boldsymbol{M}_{\mathrm{H}}=\left[\begin{array}{cc}
J_{\mathrm{m}} & 0 \\
0 & J_{s H}
\end{array}\right] \\
& \boldsymbol{K}_{\mathrm{H}}=\left[\begin{array}{cc}
k_{\mathrm{m}} & -k_{\mathrm{m}} \\
-k_{\mathrm{m}} & k_{\mathrm{m}}
\end{array}\right]
\end{aligned}
$$

where $J_{m}$ is the inertia of the rotor, and $J_{s H}$ is the inertia of $\mathrm{H}$.

The FRF in this part is calculated and represented as $h_{\mathrm{H} t 00}$. The connection between $\mathrm{A}$ and $\mathrm{H}$ is rigid coupling. The FRF of the torsional substructure is obtained by coupling the FRFs of the rotor. The FRF of the ball screw is expressed as $\boldsymbol{H}_{\mathrm{AH}-t}$.

$\boldsymbol{H}_{\mathrm{AH}-t}(l)=\left[\begin{array}{lll}h_{\mathrm{AH}-t 11}(l) & h_{\mathrm{AH}-t 12}(l) & h_{\mathrm{AH}-t 14}(l) \\ h_{\mathrm{AH}-t 21}(l) & h_{\mathrm{AH}-t 22}(l) & h_{\mathrm{AH}-t 24}(l) \\ h_{\mathrm{AH}-t 41}(l) & h_{\mathrm{AH}-t 42}(l) & h_{\mathrm{AH}-t 44}(l)\end{array}\right]=\boldsymbol{H}_{\mathrm{AB}-t}(l)+\left[\begin{array}{c}-h_{\mathrm{AB}-t 11}(l) \\ -h_{\mathrm{AB}-t 21}(l) \\ -h_{\mathrm{AB}-t 41}(l)\end{array}\right]\left[h_{\mathrm{AB}-t 11}(l)+h_{\mathrm{H}-t 00}\right]^{-1}\left[\begin{array}{c}h_{\mathrm{AB}-t 11}(l) \\ h_{\mathrm{AB}-t 12}(l) \\ h_{\mathrm{AB}-t 14}(l)\end{array}\right]^{\mathrm{T}}$

\subsection{Assembly of the Ball Screw Feed Drive System}

The overall assembly of the feed drive system is divided into three assembly states. According to the modeling characteristics of the receptance coupling, the three assembly states must adopt three worktable models, as presented in Fig. 6. The model illustrated in Fig. 6a is used for assembling the worktable and axial substructure. The model depicted in Fig. $6 \mathrm{~b}$ is used for assembling the worktable and torsional substructure. The model displayed in Fig. 6c is used for assembling the worktable and the axial and torsional substructures.

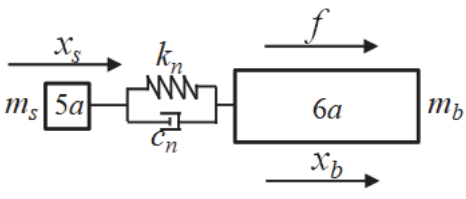

(a)

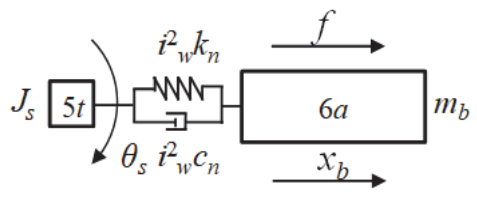

(b)

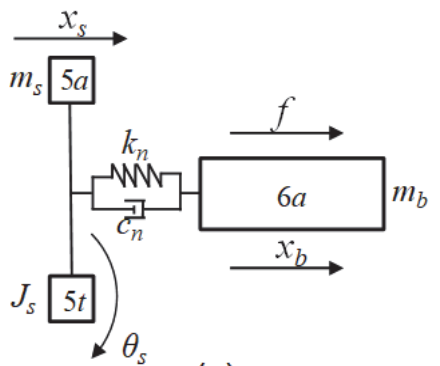

(c)

Figure 6 Worktable models for different assembly states: (a) Model of worktable coupled with axial substructure; (b) Model of worktable coupled with torsional substructure; (c) Model of worktable coupled with axial and torsional substructures

In Fig. 6, $5 a$ indicates the axis model of Segment $\mathrm{F}$ in the ball screw, $5 t$ represents the torsion model of Segment $\mathrm{F}$ in the ball screw, and $6 a$ means the model of the worktable. $m_{s}$ is the mass of Segment $\mathrm{F}, J_{s}$ is the inertia of Segment $\mathrm{F}$, and $m_{b}$ is the mass of the worktable. Coefficient $i_{b}$ is obtained through the Lagrange energy method [9], as expressed in Eq. (17). Moreover, $\mathrm{h}$ is the screw lead. $i_{b}=\frac{h}{2 \pi}$

The models illustrated in Fig. 6a and Fig. $6 \mathrm{~b}$ are only parts of the worktable substructure, and the assembly method is similar to that of the rotor. The mathematical 
model of the assembly state of the worktable and axial substructure is expressed as follows:

$$
\boldsymbol{H}_{\mathrm{AxlW}}(l)=\left[h_{\mathrm{AxlW}-6 a 6 a}(l)\right]
$$

The mathematical model of the assembly state of the worktable and torsional substructure is presented as follows:

$$
\boldsymbol{H}_{\mathrm{TorW}}(l)=\left[h_{\mathrm{TorW}-6 a 6 a}(l)\right]
$$

The model illustrated in Fig. 6c depicts the worktable substructure model of the feed drive system. FRF matrix $\boldsymbol{H}_{\mathrm{W}}$ is obtained through the finite element method.

The worktable substructure is a rigid body coupled with axial and torsional substructures. The mathematical model $H_{\text {all }}$ of the ball screw feed drive system can be

constructed through a two-step assembly. This model is also the mathematical model of the assembly state of the worktable and the axial and torsional substructures.

$$
\begin{aligned}
& \boldsymbol{H}_{\mathrm{W}}= {\left[\begin{array}{lll}
h_{\mathrm{W}-6 a 6 a} & h_{\mathrm{W}-5 a 6 a} & h_{\mathrm{W}-5 t 6 a} \\
h_{\mathrm{W}-6 a 5 a} & h_{\mathrm{W}-5 a 5 a} & h_{\mathrm{W}-5 t 5 a} \\
h_{\mathrm{W}-6 a 5 t} & h_{\mathrm{W}-5 a 5 t} & h_{\mathrm{W}-5 t 5 t}
\end{array}\right] } \\
& \boldsymbol{H}_{a w}(l)=\left[\begin{array}{lll}
h_{a w-6 a 6 a}(l) & h_{a w-5 a 6 a}(l) & h_{a w-5 t 6 a}(l) \\
h_{a w-6 a 5 a}(l) & h_{a w-5 a 5 a}(l) & h_{a w-5 t 5 a}(l) \\
h_{a w-6 a 5 t}(l) & h_{a w-5 a 5 t}(l) & h_{a w-5 t 5 t}(l)
\end{array}\right]= \\
&=\boldsymbol{H}_{\mathrm{W}}+\left[\begin{array}{c}
-h_{\mathrm{W}-6 a 5 a} \\
-h_{\mathrm{W}-5 a 5 a} \\
-h_{\mathrm{W}-5 t 5 a}
\end{array}\right]\left[\begin{array}{cc}
h_{\mathrm{W}-5 a 5 a}+h_{\mathrm{AD}-a 22}(l)
\end{array}\right]^{-1}\left[\begin{array}{l}
h_{\mathrm{W} \_5 a 6 a} \\
h_{\mathrm{W}_{-} 5 a 5 a} \\
h_{\mathrm{W} \_5 a 5 t}
\end{array}\right]^{\mathrm{T}}
\end{aligned}
$$

\section{EXPERIMENTAL VERIFICATION}

This section verifies the accuracy of the model proposed in this study by comparing experimental test data with model analysis data. The test setup is demonstrated in Fig. 7. Modal test systems (Siemens LMS SCADAS mobile and LMS test lab), an impact hammer (Kistler 9724A2000), and miniature sensors (B\&K 4525b) are utilized in the experiment.

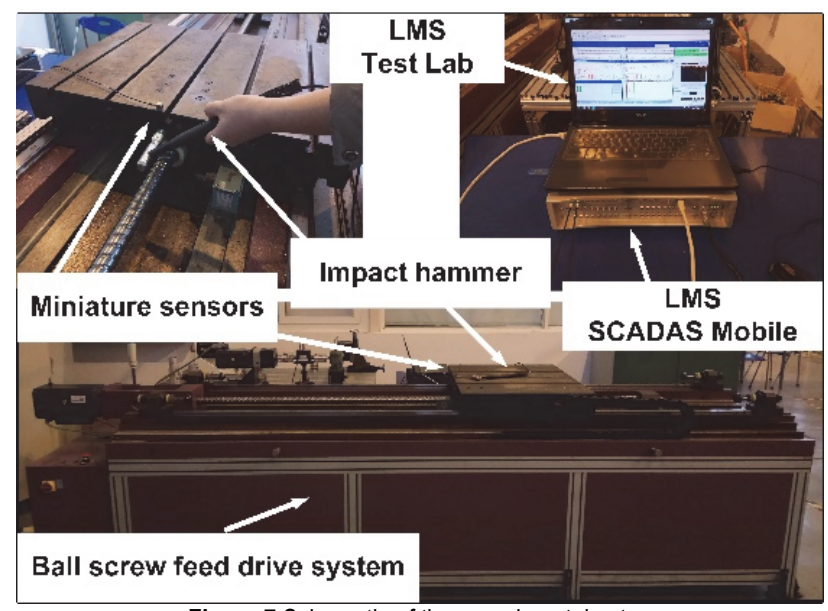

Figure 7 Schematic of the experimental setup

For the worktable position that considerably affects the dynamic characteristics of the feed drive system [16], we verify the accuracy of the model by comparing the theoretical and experimental natural frequencies at three worktable positions. Firstly, the FRF of feed drive system calculated by the mathematical model is taken as the theoretical value. Tab. 1 lists the parameters used in the modeling. Secondly, the corresponding measured FRF is obtained by modal experiment, and which is taken as the experimental value. Tab. 2 displays the experimental and theoretical values and errors of the natural frequencies. The errors of each natural frequency are all less than $3 \%$. Therefore, the model describes the dynamic characteristics of the ball screw feed drive system accurately.

\section{DYNAMIC CHARACTERISTIC ANALYSIS OF THE BALL SCREW FEED DRIVE SYSTEM}

In this section, the vibration mode of the feed drive system is determined by analyzing the natural frequency distribution of the different assembly states. The influences of worktable position, worktable mass, and screw lead on the dynamic characteristics of the feed drive system are individually analyzed in separate subsections, and the overall influence of the three parameters is synthetically analyzed in another subsection.

\subsection{Natural Frequency Distribution in the Different Assembly States}

Tab. 3 provides the natural frequencies of seven assembly states during model assembly. Such data are acquired when the worktable position is $0.7 \mathrm{~L}$, the worktable mass is $272 \mathrm{~kg}$, and the screw lead is $40 \mathrm{~mm}$.

For the axial substructure of the feed drive system, the natural frequency of the ball screw in the unassembled state is $971 \mathrm{~Hz}$, which is the axial vibration of the ball screw itself. The natural frequencies of the ball screw and bearing in the coupled assembly state are 257 and $1038 \mathrm{~Hz}$, respectively. Based on the agreement between the natural frequencies from the pure and the coupled ball screws [12], the natural frequencies of 971 and $1038 \mathrm{~Hz}$ are the same vibration mode. The natural frequency of $257 \mathrm{~Hz}$ is the coupling vibration of the ball screw and bearing. The natural frequencies of the worktable and axial substructure in the assembly state are 69 and $629 \mathrm{~Hz}$, correspondingly. No new natural frequencies are generated because the natural frequency of the coupling vibration of the worktable and axial substructure is high, thereby failing to 
reflect in the frequency band of analysis. We also verify the accuracy of our analysis by animating the model shape in finite element software. Similarly, by analyzing the torsional substructure of the feed drive system, the natural frequency of $604 \mathrm{~Hz}$ is the torsional vibration of the ball screw itself, and the natural frequency of $30 \mathrm{~Hz}$ is adopted to represent the coupling vibration of the ball screw and rotor. In summary, the first mode of the feed drive system is the coupling vibration of the ball screw and rotor. The second mode is the coupling vibration of the ball screw and bearing. The third and fourth modes are the torsional and axial vibrations of the ball screw itself, respectively.

Table 1 Parameters of the ball screw feed drive system

\begin{tabular}{|c|c|c|c|}
\hline Parameter & Value & Parameter & Value \\
\hline$E / \mathrm{Pa}$ & $2 \times 10^{11}$ & $J_{m} / \mathrm{kg} \cdot \mathrm{m}^{2}$ & $1 \times 10^{-3}$ \\
\hline$G / \mathrm{Pa}$ & $7.75 \times 10^{10}$ & $c_{a l} / \mathrm{N} \cdot \mathrm{s} / \mathrm{m}$ & $7.09 \times 10^{8}$ \\
\hline$\rho / \mathrm{kg} / \mathrm{m}^{3}$ & $7.85 \times 10^{3}$ & $k_{a l} / \mathrm{N} / \mathrm{m}$ & $2.25 \times 10^{3}$ \\
\hline$d / \mathrm{m}$ & $4 \times 10^{-2}$ & $c_{a l} / \mathrm{N} \cdot \mathrm{s} / \mathrm{m}$ & $4.28 \times 10^{7}$ \\
\hline$h / \mathrm{m}$ & $4 \times 10^{-2}$ & $k_{a r} / \mathrm{N} / \mathrm{m}$ & $2.02 \times 10^{3}$ \\
\hline$m_{s} / \mathrm{kg}$ & 0.25 & $c_{a r} / \mathrm{N} \cdot \mathrm{s} / \mathrm{m}$ & $2.94 \times 10^{7}$ \\
\hline$J_{s} / \mathrm{kg} \cdot \mathrm{m}^{2}$ & $1 \times 10^{-4}$ & $k_{m} / \mathrm{N} \cdot \mathrm{m} / \mathrm{rad}$ & $2.73 \times 10^{3}$ \\
\hline$J_{s j} / \mathrm{kg} \cdot \mathrm{m}^{2}$ & $1 \times 10^{-4}$ & $c_{m} / \mathrm{N} \cdot \mathrm{m} \cdot \mathrm{s} / \mathrm{rad}$ & $5.53 \times 10^{3}$ \\
\hline$m_{b} / \mathrm{kg}$ & $2.72 \times 10^{2}$ & 3.50 \\
\hline
\end{tabular}

Table 2 Comparison of the theoretical natural frequencies and experimental values at three positions

\begin{tabular}{|c|c|c|c|c|c|}
\hline \multirow{2}{*}{ Positions } & \multicolumn{5}{|c|}{ Natural frequency / Hz } \\
\hline & & First mode & Second mode & Third mode & Fourth mode \\
\hline \multirow{3}{*}{$l_{1}=0.6 \mathrm{~m}$} & Experimental & 24 & 118 & 523 & 716 \\
\hline & Theoretical & 24 & 116 & 520 & 713 \\
\hline & Error & $0.00 \%$ & $1.69 \%$ & $0.57 \%$ & $0.42 \%$ \\
\hline \multirow{3}{*}{$l_{2}=1.0 \mathrm{~m}$} & Experimental & 24 & 116 & 565 & 721 \\
\hline & Theoretical & 24 & 115 & 577 & 719 \\
\hline & Error & $0.00 \%$ & $0.86 \%$ & $-2.12 \%$ & $0.28 \%$ \\
\hline \multirow{3}{*}{$l_{3}=1.6 \mathrm{~m}$} & Experimental & 23 & 113 & 561 & 728 \\
\hline & Theoretical & 23 & 115 & 573 & 736 \\
\hline & Error & $0.00 \%$ & $-1.77 \%$ & $-2.14 \%$ & $-1.10 \%$ \\
\hline
\end{tabular}

Table 3 Natural frequency distribution in different assembly states

\begin{tabular}{|c|c|c|c|c|c|}
\hline \multirow{2}{*}{\multicolumn{2}{|c|}{ Assembly states }} & \multicolumn{4}{|c|}{ Natural frequency / Hz } \\
\hline & & \multirow{2}{*}{$\begin{array}{c}\text { First mode } \\
-—\end{array}$} & \multirow{2}{*}{$\begin{array}{c}\text { Second mode } \\
--\end{array}$} & \multirow{2}{*}{$\begin{array}{c}\text { Third mode } \\
--\end{array}$} & \multirow{2}{*}{$\begin{array}{c}\text { Fourth mode } \\
971\end{array}$} \\
\hline & Ball screw & & & & \\
\hline Axial substructure & Ball screw + bears & - & 257 & -— & 1038 \\
\hline \multicolumn{2}{|c|}{ Axial substructure + worktable } & -— & 69 & -— & 629 \\
\hline \multirow{2}{*}{ Rotation substructure } & Ball screw & -— & -二 & 604 & -二 \\
\hline & Ball screw + rotor & 30 & -二 & 594 & -二 \\
\hline \multicolumn{2}{|c|}{ Rotational substructure + worktable } & 19 & -二 & 421 & -二 \\
\hline \multicolumn{2}{|c|}{ Ball screw feed drive system } & 24 & 114 & 545 & 736 \\
\hline
\end{tabular}

\subsection{Influence of Worktable Position}

The influence of worktable position on the dynamic characteristics is analyzed in this subsection. FRFs are obtained using the mathematical model of the feed drive system at different worktable positions, as exhibited in Fig. 8 . The maximum and minimum values of the natural frequencies are presented in Tab. 4.

Table 4 Influence of natural frequencies by worktable position

\begin{tabular}{|c|c|c|c|c|}
\hline \multirow{2}{*}{} & \multicolumn{4}{|c|}{ Natural frequency / Hz } \\
\cline { 2 - 5 } & First mode & $\begin{array}{c}\text { Second } \\
\text { mode }\end{array}$ & Third mode & Fourth mode \\
\hline Min & 23 & 113 & 474 & 693 \\
\hline Max & 24 & 116 & 599 & 738 \\
\hline Change rate & $4.35 \%$ & $2.65 \%$ & $26.37 \%$ & $6.49 \%$ \\
\hline
\end{tabular}

The FRF curves of the ball screw feed system of all worktable positions are combined, and the FRF peak of each mode forms a curve, as displayed in Fig. 8. The effect of worktable position on each mode is intuitively understood through Fig. 8. If the curve that corresponds to a certain mode is parallel to the coordinate axis of the position, the worktable position slightly influences this mode. If the curve of another mode is not parallel to the coordinate axis of the position, then the influence of the worktable on this mode is substantial.

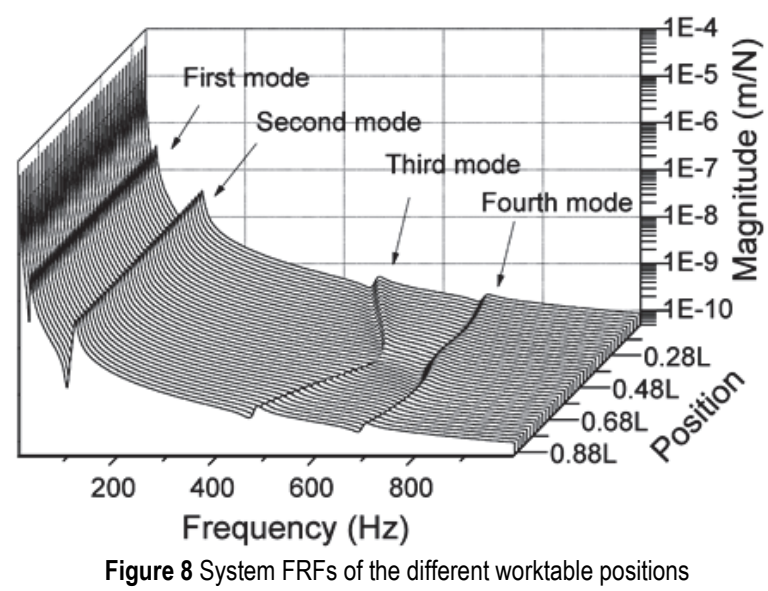

The natural frequencies of the first and second modes of the feed drive system slightly change with the worktable position from Fig. 8. By contrast, the natural frequencies of the third and fourth modes considerably change. The third and fourth modes are the torsional and axial vibrations of the ball screw itself, respectively. The worktable position 
corresponds to the position of the screw nut, which is regarded as the constraint of the worktable on the ball screw. A change in worktable position is equivalent to a change in constraint position on the ball screw. According to the two analyses, a change in worktable position considerably influences the vibration of the ball screw itself.

The first mode is the coupling vibration of the rotor and ball screw. The second mode is the coupling vibration of the ball screw and bearing. The change in worktable position is slightly related to both kinds of coupled vibration.

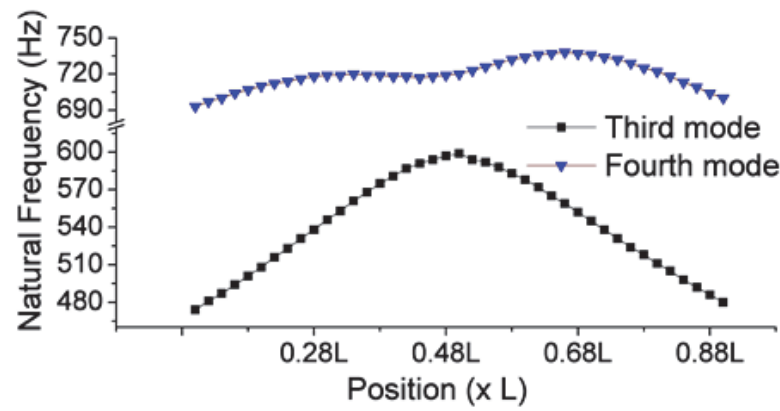

Figure 9 Influence of worktable position on the natural frequencies of the third and fourth modes

The variation in the natural frequencies of the third and fourth modes with the worktable position is demonstrated in Fig. 9. The basic rule of the change in the two natural frequencies is high in the middle position and low on both sides. The worktable in the middle position and the ball screw length between the constraint position and both ends are the same. When the worktable moves to the right, the left ball screw of the worktable is lengthened, and the right ball screw is shortened. Therefore, the natural frequencies of the torsional and axial vibrations of the ball screw itself decrease, thus implying that such frequencies of the third and fourth modes of the corresponding feed drive system also decrease. Therefore, the basic rule (high in the middle and low on both sides) exists. The curve of the fourth mode deforms (the highest point is not in the middle) because the fourth mode of the feed drive system is the axial vibration of the ball screw itself, and the magnitude of the axial stiffness of the bearing at both ends of the ball screw is different. The third mode has a larger variation range of the natural frequency than the fourth mode because the ball screw is a slender shaft, and its torsional stiffness is less than that of the axial stiffness.

\subsection{Influence of Worktable Mass}

Worktable mass is also an important parameter in designing the feed drive system. Therefore, the influence of worktable mass on the dynamic characteristics of the feed drive system is analyzed in this subsection. The FRFs are obtained using the mathematical model of the system with different worktable masses, which are exhibited in Fig. 10. The influence rule of worktable mass on the natural frequency of the system is not evident.

In Tab. 5, the natural frequencies display more changes in the first and second modes of the feed drive system than in the third and fourth modes given the increase in worktable mass.

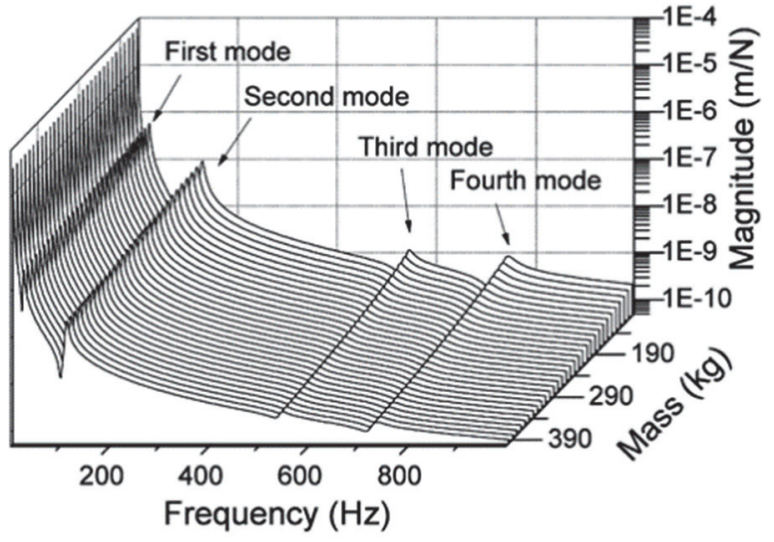

Figure 10 System FRFs of the different worktable masses

Table 5 Influence of the natural frequencies caused by worktable mass

\begin{tabular}{|c|c|c|c|c|}
\hline \multirow{2}{*}{} & \multicolumn{4}{|c|}{ Natural frequency $/ \mathrm{Hz}$} \\
\cline { 2 - 5 } & First mode & $\begin{array}{c}\text { Second } \\
\text { mode }\end{array}$ & Third mode & $\begin{array}{c}\text { Fourth } \\
\text { mode }\end{array}$ \\
\hline Min & 23 & 109 & 578 & 741 \\
\hline Max & 26 & 132 & 581 & 763 \\
\hline Change rate & $13.04 \%$ & $21.10 \%$ & $0.52 \%$ & $2.97 \%$ \\
\hline
\end{tabular}

In this coupled system, the natural frequencies of the feed drive system can inevitably decrease with the increase in mass when the other conditions remain unchanged, as presented in Fig. 11. The third and fourth vibrations are related mainly to the worktable position, which remains unchanged with the worktable mass. Therefore, the change in the worktable mass only slightly influences the vibration of the third and fourth modes of the feed drive system.

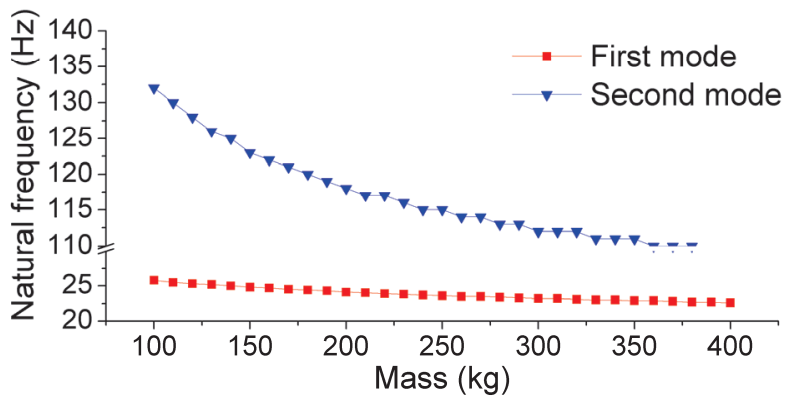

Figure 11 Influence of worktable mass on the natural frequencies of the first and second modes

\subsection{Influence of Screw Lead}

Screw lead is another important parameter in designing a ball screw feed drive system. The screw lead is set to change within its common range $(10-50 \mathrm{~mm})$. The obtained FRFs of the feed drive system are illustrated in Fig. 12; these FRFs correspond to the different screw leads. The influence of each mode caused by screw lead is depicted in Fig. 13, and Tab. 6 lists the change rate of the natural frequencies caused by the change in screw lead.

Table 6 Influence of the natural frequencies caused by the screw lead

\begin{tabular}{|c|c|c|c|c|}
\hline \multirow{2}{*}{} & \multicolumn{4}{|c|}{ Natural frequency / Hz } \\
\cline { 2 - 5 } & First mode & Second mode & Third mode & Fourth mode \\
\hline Min & 23 & 74 & 532 & 676 \\
\hline $\begin{array}{c}\text { Max } \\
\text { rate }\end{array}$ & 28 & 129 & 586 & 758 \\
\hline
\end{tabular}


According to Fig. 12 and Tab. 6, the screw lead has the most complex influence on the dynamic characteristics of the ball screw feed drive system. The size of the screw lead corresponds to the helical angle of the ball screw. The size of the helical angle determines the influence of the worktable on the dynamic characteristics of the axial and torsional substructures. Therefore, the change in the screw lead influences the dynamic characteristics of the axial and torsional substructures. That is, the change in screw lead can affect the natural frequency of each mode.

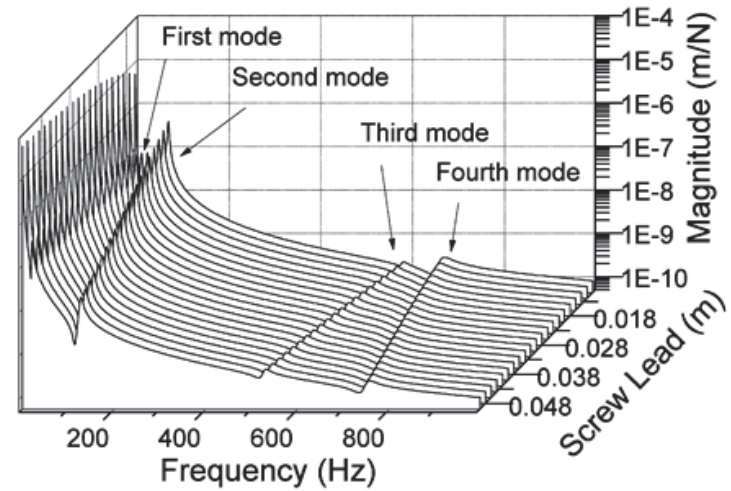

Figure 12 System FRFs of the different screw leads

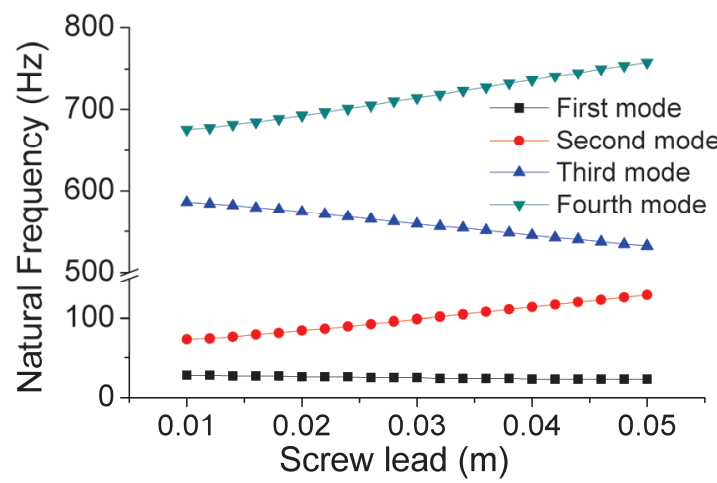

Figure 13 Influence of the natural frequencies caused by the screw lead

According to the analysis above, the first and third modes are caused by torsional vibration, and the second and fourth modes are caused by axial vibration. Therefore, according to the analysis presented in Figs. 12 and 13, the effects of worktable on the axial and torsional substructures are opposite. This result can be explained by the force analysis.

\subsection{Influence of Multiple Factors on Dynamic Characteristics}

The overall influence of worktable position, worktable mass, and screw lead on the dynamic characteristics of the ball screw feed drive system is analyzed in this subsection. The natural frequencies of the two types of screw lead are selected for analysis, as illustrated in Fig. 14.

The natural frequencies of the first and second modes are presented as a streak along the direction of the position change, as depicted in Fig. 14. This change is caused by the slight influence of the worktable position on the first and second modes of the system. Considering the increase in the screw lead, the first mode decreases, and the variation range widens. These rules are caused by the enhanced influence of the worktable substructure on the torsional substructure.

The analysis methods of the third and fourth modes are similar to those of the first and second modes. Therefore, the former is not described in detail.

$\delta_{i} \cdot \sqrt{\sum \delta_{i n}^{2}}$

Tab. 7 summarizes the maximum and minimum natural frequencies of the ball screw feed drive system obtained given simultaneous changes in the abovementioned factors. The change rate of each mode and the overall change rate with each screw lead are calculated. The overall change rate can be obtained using Eq. (23), where $\delta_{\text {in }}$ represents the change rate of the $n$-th mode when the lead is $h_{i}$, and $\delta_{i}$ represents the overall change rate when the lead is $h_{i}$. The overall change rate of the natural frequency of the ball screw feed drive system decreases with the increase in the screw lead. Therefore, in the common range of the screw lead, the stability of the feed drive system is enhanced with the increase in the screw lead.
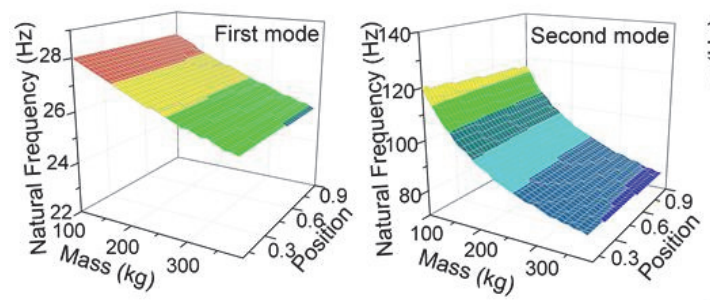

(a)
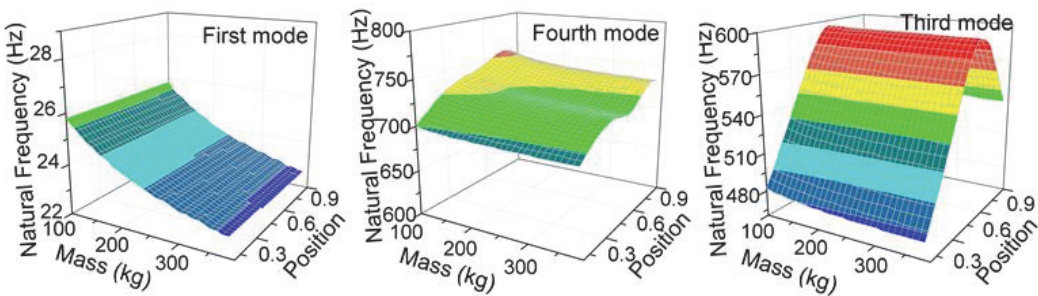

(b)
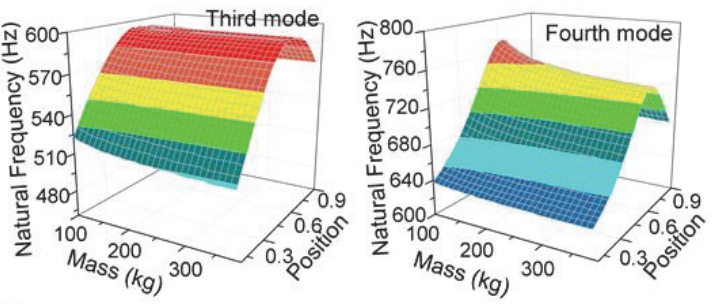

Figure 14 Influence of multiple factors on the natural frequency: (a) $h_{2}=0.02 \mathrm{~m}$, (b) $h_{4}=0.04 \mathrm{~m}$ 
Table 7 Influence of worktable position, worktable mass, and screw lead on the natural frequency

\begin{tabular}{|c|c|c|c|c|c|c|}
\hline \multirow{2}{*}{ Screw lead } & & \multicolumn{4}{|c|}{ Natural frequency / Hz } & \multirow{2}{*}{ Overall change rate } \\
\hline & & First mode & Second mode & Third mode & Fourth mode & \\
\hline \multirow{3}{*}{$h_{1}=0.02 \mathrm{~m}$} & Max & 28 & 120 & 595 & 745 & \\
\hline & Min & 25.3 & 76 & 510 & 631 & \\
\hline & Change rate & $10.67 \%$ & $57.89 \%$ & $16.67 \%$ & $18.07 \%$ & $63.80 \%$ \\
\hline \multirow{3}{*}{$h_{2}=0.03 \mathrm{~m}$} & Max & 26.9 & 128 & 596 & 762 & \\
\hline & Min & 23.7 & 92 & 490 & 661 & \\
\hline & Change rate & $10.67 \%$ & $39.13 \%$ & $21.63 \%$ & $15.28 \%$ & $49.14 \%$ \\
\hline \multirow{3}{*}{$h_{3}=0.04 \mathrm{~m}$} & Max & 25.8 & 138 & 595 & 756 & \\
\hline & Min & 22.6 & 108 & 472 & 692 & \\
\hline & Change rate & $14.16 \%$ & $27.78 \%$ & $26.06 \%$ & $9.25 \%$ & $41.67 \%$ \\
\hline \multirow{3}{*}{$h_{4}=0.05 \mathrm{~m}$} & $\operatorname{Max}$ & 24.9 & 148 & 595 & 752 & \\
\hline & Min & 22 & 124 & 457 & 721 & \\
\hline & Change rate & $13.18 \%$ & $19.35 \%$ & $30.20 \%$ & $4.30 \%$ & $38.45 \%$ \\
\hline
\end{tabular}

\section{CONCLUSIONS}

In this study, the mathematical model of a ball screw feed drive system is established by receptance coupling, and the dynamic characteristics are analyzed through the proposed method. The relevant conclusion provides a theoretical basis for the design and improvement of ball screw feed drive system. The main conclusions are drawn as follows:

This study improves the modeling method for the single-axis feed drive system to be modeled by receptance coupling. The natural frequency error of the first four modes of the feed drive system is less than $3 \%$ by comparing theory and experiment values. This modeling method is accurate and effective.

The vibration modes of the feed drive system are analyzed through the natural frequency distribution of seven assembly states. The first mode is the coupling vibration of the screw and rotor, the second is coupling vibration of the screw and bearing, and the third and fourth are the torsional and axial vibrations of the ball screw itself, respectively.

The change in worktable position mainly affects the modal caused by the vibration of the ball screw itself. The change in worktable mass mainly affects the modal caused by the coupling vibration between the ball screw and rotor or bearing.

The natural frequency caused by the axial vibration increases with the screw lead, whereas that caused by the torsional vibration decreases with the screw lead. The stability of the feed drive system increases with the screw lead in accordance with the overall influence of worktable position, worktable mass, and screw lead on the natural frequency of the feed drive system.

\section{Acknowledgments}

This work is supported by the Natural Science Foundation of China [Grant No. 51775323]; Research project of Shanghai Science and Technology Commission [Grant No. 17060502600]. The authors are grateful to other project participants for their cooperation and endeavor.

\section{REFERENCES}

[1] Zhu, J. M., Zhang, T. C., Wang, J., \& Li, X. R. (2016). Axial dynamic characteristic parameters identification of rolling joints in a ball screw feed drive system. Proceedings of the Institution of Mechanical Engineers Part C - Journal of Engineering Science, 230(14), 2449-2462.

\section{https://doi.org/10.1177/0954406215597955}

[2] Xu, Z. Z., Liu, X. J., Choi, C. H., \& Lyu, S. K. (2013). A novel high speed/high precision ball screw. International Journal of Precision Engineering and Manufacturing, 4(1), 165-167. https://doi.org/10.1007/s12541-013-0023-0

[3] Chen, J. S., Huang, Y. K., \& Cheng, C. C. (2004). Mechanical model and contouring analysis of high-speed ball-screw drive systems with cmpliance effect. International Journal of Advanced Manufacturing Technology, 24(3-4), 241-250. https://doi.org/10.1007/s00170-003-1777-9

[4] Feng, G. H. \& Pan, Y. L. (2011). Investigation of ball screw preload variation based on dynamic modeling of a preload adjustable feed-drive systemand spectrum analysis of ballnuts sensedvibration signals. International Journal of Machine Tools \& Manufacture, 52(1), 85-96. https://doi.org/10.1016/j.jimachtools.2011.09.008

[5] Okwudire, C. E. \& Altintas, Y. (2009). Hybrid modeling of ball screw drives with coupled axial, torsional, and later dynamics. Journal of Mechanical Design, 131(7), 071002. https://doi.org/10.1115/1.3125887

[6] Lin, X. K., Liu, T., \& Wang, J. (2018). Optimization of servo parametes for enhanced dynamic behavior of direct feed system with hybrid FEM and PLS regression. International Journal of Precision Engineering and Manufacturing, 19(11), 1627-1636. https://doi.org/10.1007/s12541-018-0190-0

[7] Zhang, H. J., Zhang, J., Liu, H., Liang, T., \& Zhao, W. H. (2015). Dynamic modeling and analysis of the high-speed ball screw feed system. Proceedings of the Institution of Mechanical Engineers, Part B: Journal of Engineering Manufacture, 229(5), 870-877. https://doi.org/10.1177/0954405414534641

[8] Zhou, Y., Peng, F. Y., \& Wang, G. X. (2013). A study on the dynamic characteristics of the drive at center of gravity (DCG) feed drives. International Journal of Advanced Manufacturing Technology, 66(1-4), 325-336. https://doi.org/10.1007/s00170-012-4327-5

[9] Frey, S., Dadalau, A., \& Verl, A. (2012). Expedient modeling of ball screw feed drives. Production Engineering, 6(2), 205-211. https://doi.org/10.1007/s11740-012-0371-0

[10] Varanasi, K. K. \& Nayfeh, S. A. (2004). The dynamics of lead-screw drives: Low-order modeling and experiments. Journal of Dynamic Systems, Measurement and Control, 126(2), 388-396. https://doi.org/10.1115/1.1771690

[11] Dong, L. \& Tang, W. C. (2013). Hybrid modeling and analysis of structural dynamic of a ball screw feed drive system. Mechanika, 19(3), 316-323. https://doi.org/10.5755/j01.mech.19.3.4662

[12] Vicente, D. A., Hecker, R. L., Villegas, F. J., \& Flores, G. M. (2012). Modeling and vibration mode analysis of a ball screw drive. International Journal of Advanced Manufacturing Technology, 58(1-4), 257-265. https://doi.org/10.1007/s00170-011-3375-6

[13] Wang, E. H., Wu, B., Hu, Y. M., Yang, S. Z., \& Cheng, Y. (2013). Dynamic parameter identification of tool-spindle 
interface based on RCSA and Particle Swarm Optimization. Shock and Vibration, 20(1), 69-78. https://doi.org/10.1155/2013/634528

[14] Movahhedy, M. R. \& Gerami, J. M. (2006). Prediction of spindle dynamics in milling by sub-structure coupling. International Journal of Machine Tools \& Manufacture, 46(3-4), 243-251.

https://doi.org/10.1016/j.jimachtools.2005.05.026

[15] Ozsahin, O., Erturk, A., Ozguven, H., \& Budak, E. (2009). A closed-form approach for identification of dynamical contact parameters in spindle-holder-tool assemblies. International Journal of Machine Tools \& Manufacture, 49(1), 25-35. https://doi.org/10.1016/j.jimachtools.2008.08.007

[16] Liu, H., Lu, D., Zhang, J., \& Zhao, W. H. (2017). Receptance coupling of multi-subsystem connected via a wedge mechanism with application in the position-dependent dynamics of ballscrew drives. Journal of Sound and Vibration, 376, 166-181.

https://doi.org/10.1016/j.jsv.2016.04.020

[17] Zhang, L., Wang, T. Y., Wang, G. F., \& Tian, S. L. (2017). Hybrid dynamic modeling and analysis of a ball-screw-drive spindle system. Journal of Mechanical Science and Technology, 31, 4611-4618. https://doi.org/10.1007/s12206-017-0907-5

[18] Schmitz, T. L. \& Smith, K. S. (2012). Mechanical vibrations: modeling and measurement. Springer.

https://doi.org/10.1007/978-1-4614-0460-6

\section{Contact information:}

\section{Fengqing TIAN}

School of Mechanical Engineering,

University of Shanghai for Science and Technology,

Shanghai 200093, China

\section{Jianmin ZHU}

(Corresponding author)

School of Mechanical Engineering,

University of Shanghai for Science and Technology,

Shanghai 200093, China

E-mail: jmzhu6688@126.com

\section{Xiaoru LI}

School of Mechanical Engineering,

University of Shanghai for Science and Technology,

Shanghai 200093, China

\section{Zhiwen HUANG}

School of Mechanical Engineering,

University of Shanghai for Science and Technology,

Shanghai 200093, China 